\title{
JULIA KRISTEVA E A SEMANÁLISE: DOS DIALOGISMOS ÀS SIGNIFICÂNCIAS
}

\author{
Julia Kristeva and semanalysis: from dialogisms to significances \\ Julia Kristeva y la semanálisis: de los dialogismos a las significancias \\ Cássio de Borba Lucas \\ Doutorando pelo PPGCOM-UFRGS, bolsista CAPES \\ cassioborba@gmail.com
}

\author{
Alexandre Rocha da Silva \\ Professor do PPGCOM-UFRGS \\ arsrocha@gmail.com
}

\section{Resumo}

O trabalho recolhe e discute as principais teses e contribuições da obra de Julia Kristeva em relação ao desafio pós-estruturalista da investigação em comunicação como uma questão menos de gramática e transmissão do que de micropolítica. Para tanto, passa dos dialogismos da comunicação, por suas teses fundantes (principalmente Bakhtin), à sua reformulação como intertextualidade (Kristeva e Barthes) no seio da lógica de significância. Esta, entendida como o fundamento, mas também como o devir da significação, é apresentada por suas relações com a textualidade e com o par conceitual fenotexto/genotexto, que constitui práticas significantes. Com isso, chegamos à ênfase da semanálise na produtividade e no trabalho que a comunicação pode investigar não somente como significação, mas como elaboração e problematização do sentido.

Palavras-chave: Dialogismo. Intertextualidade. Significância.

\begin{abstract}
This article harvests and discusses the main theses and contributions of the works of Julia Kristeva in face of the post-structuralist challenge of investigating communications as a question of micropolitics rather than of gramaticalities and transmission. To do so, it departs from the dialogisms of communication (in its founding theses, mainly Bakhtin) towards its reformulation as intertextualities (Kristeva and Barthes) working in a logic of significance. This significance, understood as the foundation, but also as the becoming (devenir) of signification, is presented through its relations with textuality and the pairs phenotext/genotext and semiotic/symbolic which constitute signifying practices. This leads us to the emphasis of semanalysis in the productivity and the work (travail) that communication studies may investigate not only as signification, but as an elaboration and problematization of sense.
\end{abstract}

Key words: Dialogism. Intertextuality. Significance. 


\section{Resumen}

El trabajo recoge y discute las principales tesis y contribuciones de la obra de Julia Kristeva en relación al desafío post-estructuralista de la investigación en comunicación como una cuestión menos de gramática y transmisión que de micropolítica. Por lo tanto, pasa de los dialogismos de la comunicación, por sus tesis fundantes (principalmente Bakhtin), a su reformulación como intertextualidad (Kristeva y Barthes) en el seno de la lógica de significancia. Esta, entendida como el fundamento, pero también como el devenir de la significación, es presentada por sus relaciones con la textualidad y con el par fenotexto/genotexto que constituye prácticas significantes. Con eso, llegamos al énfasis de la semanálisis en la productividad y en el trabajo que la comunicación puede investigar no sólo como significación, sino como elaboración y problematización del sentido.

Palabras clave: Dialogismo. Intertextualidad. Significancia.

\section{INTRODUÇÃO}

O propósito deste artigo é apresentar aspectos importantes do pensamento semiótico de Julia Kristeva. Pretendemos, com isso, compreender sua proposta fundamental de investigação semiótica (ou "semanalítica") não só da significação, mas da significância. Para chegarmos a uma apresentação problematizante, optamos por apresentar esta passagem pelo eixo das discussões em torno do conceito de dialogismo. Tal conceito será revisado, na obra kristevana, como intertextualidade e transposição, convocando a discussão de outras noções como a de texto e o par conceitual fenotexto e genotexto, dimensões constitutivas das práticas significantes.

A dimensão propriamente semiótica da significância não se reduz ao estudo do aspecto estruturado da comunicação, que significa por meio de códigos, que transmite uma mensagem a um receptor. As estruturalidades da comunicação, estas regularidades que constituíam os sistemas de signos estudados pela semiologia estrutural, formam práticas significantes (KRISTEVA, 1975) cuja estabilidade fenotextual é constantemente ameaçada por um movimento semiótico de destruição, reelaboração, trabalho transpositivo, os quais a autora pretendia estudar como genotexto. $\mathrm{O}$ genotexto e o fenotexto são categorias decisivas para o estudo dos movimentos de significância da comunicação, tese que nos parece a mais importante contribuição kristevana para a semiótica contemporânea.

Mas só chegamos a estas teses a partir do estudo das definições de intertextualidade, da qual a significância é indissociável, e que por sua vez nos conduzia na direção de outras teses importantes acerca da natureza dialógica da linguagem e da comunicação. É nesta cadeia 
de reflexões que pretendemos nos situar aqui, para apresentar a proposta kristevana da passagem dos estudos de significação aos de significância. Em um primeiro bloco, apresentamos as teses fundantes e as discussões sobre os conceitos de dialogismo e intertextualidade para, no segundo bloco, indicarmos as problematizações que a perspectiva da significância propõe para os estudos da intertextualidade da comunicação.

\section{DIALOGISMO E INTERTEXTUALIDADE}

Encontramos as raízes mais profundas (histórica ou genealogicamente falando) do conceito de intertextualidade na linguística e na literatura - nas quais, contudo, ele parece ter sempre tentado provocar um tipo de estranhamento, de afastamento ou de escape. Julia Kristeva - que, como se sabe, utiliza o termo pela primeira vez, transcriando na Europa nãosoviética as ideias de Mikhail Bakhtin - já reservava para a intertextualidade o lugar em uma “translinguística” (KRISTEVA, 2012, pp. 10, 70-71), como se verá melhor adiante. Mas mesmo o conceito bakhtiniano de dialogismo, ao qual a literatura sempre reserva o ponto de origem da intertextualidade ${ }^{1}$, era pensado pelo autor russo como parte de uma "metalinguística", que estuda "aqueles aspectos da vida do discurso que ultrapassam [...] os limites da lingüística" (BAKHTIN, 1984, p. 181). Bakhtin pretendia se afastar, assim, dos "fenômenos puramente lingüísticos" associados ao "plano da língua", que "em hipótese alguma" podem abordar "a especificidade das relações dialógicas entre as réplicas" (BAKHTIN, 1984, p. 182).

A língua, da perspectiva linguística que Bakhtin recusava (não por falta de cientificidade, mas de abrangência), é uma estrutura, ou seja, uma "entidade autônoma de dependências internas", de "princípios inerentes" ou "leis sincrônicas" (HJELMSLEV, 1991, pp. 33 e 31). Nesse plano da linguística geral, em que a língua aparece como código que faz corresponder significantes a significados (DUCROT \& TODOROV, 1972, p. 156), a identificação de regularidades da língua tem primazia sobre as variações que aparecem em sua manifestação concreta $^{2}$. Esta atividade de manifestação - isto que, da perspectiva estruturalista, seria a aplicação da língua - Saussure (1995, p. 30) denominava "fala".

\footnotetext{
${ }^{1}$ MOI, 1986, p. 34; SAMOYAULT, 2008, p. 15; MOTTA, 2011, p. 197, entre outros.

${ }^{2}$ Saussure (1995, p. 25) afirma que « il faut se placer de prime abord sur le terrain de la langue et la prendre pour norme de toutes les autres manifestations du langage », e Hjelmslev (1991, p. 33) que « [a linguística estrutural] considera a fala subordinada à língua ».
} 
Por sua vez, Bakhtin centrou-se no conceito traduzido como "discurso", recorrente e fundamental em suas reflexões sobre o dialogismo:

temos em vista o discurso, ou seja, a língua em sua integridade concreta e viva e não a língua como objeto específico da lingüística, obtido por meio de uma abstração (BAKHTIN, 1984, p. 183).

E também:

as relações dialógicas são extralingüísticas. Ao mesmo tempo, porém, não podem ser separadas do campo do discurso, ou seja, da língua enquanto fenômeno integral concreto (BAKHTIN, 1984, p. 183)

Bakhtin, contudo, procura se afastar da "generalidade" com que "a lingüística estuda a linguagem", ou seja: procura não lançar mão da abstração que faz com que a língua, de caráter social, passivo-associativo e codificado, tenha primazia sobre o caráter singular, ativo e variável de uma materialização discursiva (BAKHTIN, 1984, p. 183).

Uma vez esclarecido seu objeto de interesse - o discurso assim definido como concreção ou "língua in actu" (BAKHTIN, 2016, p. 117) -, Bakhtin pode estabelecer o postulado de que "o discurso [...] é por natureza dialógico" (BAKHTIN, 1984, p. 183 e BAKHTIN, 2016, p. 116). O dialogismo aparece, pois, não como um fenômeno localizado: trata-se de um fundamento característico da natureza de toda comunicação. Daí a irrelevância de trabalhos que apontam para o caráter dialógico em seu objeto de análise, para concluir: 'eis aqui um dialogismo’. Este é, ao contrário, “característica essencial da linguagem e princípio constitutivo, muitas vezes mascarado, de todo discurso. $\mathrm{O}$ dialogismo é a condição do sentido do discurso" (BARROS, 1999, p. 2). A citação extensa de Bakhtin é esclarecedora:

Um membro de um grupo falante nunca encontra previamente a palavra como uma palavra neutra da língua, isenta das aspirações e avaliações de outros ou despovoada das vozes dos outros. Absolutamente. A palavra ele a recebe da voz de outro e repleta de voz de outro. No contexto dele, a palavra deriva de outro contexto, é impregnada de elucidações de outros. O próprio pensamento dele já encontra a palavra povoada (BAKHTIN, 1984, p. 202).

O autor passa, pois, a conceber o dialogismo como "fundo perceptivo" mesmo da “atividade mental” (BAKHTIN, 1997, p. 147 e BAKHTIN, 2016, p. 132). "Aquele que apreende a enunciação de outrem não é um ser mudo, privado da palavra, mas ao contrário um ser cheio de palavras interiores". O que se ouve, lê, compreende - de uma perspectiva dialógica - é sempre "mediatizado [...] pelo discurso interior". "A palavra vai à palavra" (BAKHTIN, 1997, p. 147). 
A passagem de um texto considerado por suas relações internas (intratextualidade) à consideração de sua intertextualidade aparece na obra de Bakhtin também por sua oposição entre discursos monológicos e dialógicos. O caráter dialógico, embora fundante, como vimos, da discursividade, pode, porém, ser suprimido, ainda que, em aparência, nos discursos de caráter "monológico". Ao discurso monológico, aliás, está ligada a própria consciência individual, produzida sob a forma de monólogo interior que aliena o caráter social da linguagem: "como o corpo se forma inicialmente dentro do seio materno (corpo), assim a consciência do homem desperta envolvida na consciência alheia" (BAKHTIN apud LEMOS, 1999, p. 39). Entre discurso e monólogo, "há constantes transições" (BAKHTIN, 2016, p. 131): “cada monólogo é a réplica de um grande diálogo" (BAKHTIN, 2016, p. 92).

É seguindo nesta via que a teoria de Bakhtin desemboca numa crítica ideológica do fenômeno comunicacional. Os discursos retomados, os 'outros textos' e 'outras vozes', de um lado; "e o contexto de transmissão", de outro, "são somente os termos de uma inter-relação dinâmica. Essa dinâmica, por sua vez, reflete a dinâmica da inter-relação social dos indivíduos na comunicação ideológica" (BAKHTIN, 1997, p. 148), que é determinada pelas "condições sociais e econômicas da época" (BAKHTIN, 1997, p. 154). O que não significa escapar à imanência da análise discursiva: "o contexto" não é um 'fora da linguagem', mas "uma rede de textos da cultura que dialogam de modo contratual e conflitante" (BARROS, 1999, p. 5). A ideologia da comunicação torna-se, destarte, foco privilegiado da metalingüística:

O monologismo, isto é, a concentração da obra em torno da voz do autor, constitui um artifício de que este lança mão para centrar tudo em seu próprio núcleo ideológico. A tarefa do estudioso da literatura seria desvendar esse dialogismo essencial (LOPES, 1999, p. 64).

Preterindo a descrição das "orientações da dinâmica da inter-relação da enunciação e do discurso citado" (BAKHTIN, 1997, p. 150), nos questionamos acerca desta expressividade da intertextualidade como diálogo de vozes a partir da oposição entre discursos monovocais e bivocais. Por oposição aos primeiros, que são diretos e orientados para seu objeto (BAKHTIN, 1984, p. 186), a palavra, nos discursos bivocais,

tem duplo sentido, voltada para o objeto do discurso enquanto palavra comum e para um outro discurso, para o discurso de um outro. Se desconhecermos a existência desse segundo contexto do discurso do outro e começarmos a interpretar a estilização ou a paródia como interpretamos o discurso comum voltado exclusivamente para o seu objeto, não entenderemos verdadeiramente esses fenômenos: a estilização será 
interpretada como estilo, a paródia, simplesmente como obra má." (BAKHTIN, 1984, p. 185)

O autor descreverá vários tipos de discursos bivocais, passando por gêneros obscuros para o leitor ocidental, como o "skaz". Torna-se necessário que nos baseemos no estudo de Fiorin (1999), que distingue os fenômenos de "presença de duas vozes num mesmo segmento discursivo ou textual" (FIORIN, 1999, p. 30) em intertextualidade e interdiscursividade.

A intertextualidade pode ser de três tipos: citação, alusão e estilização. A citação pode "confirmar ou alterar" o sentido do texto com o qual se dialoga (FIORIN, 1999, p. 30), mas retoma as palavras deste com rigor. $\mathrm{Na}$ alusão, as palavras não são citadas, mas "reproduzemse construções sintáticas em que certas figuras são substituídas por outras”, podendo-se estabelecer uma polêmica com o intertexto a que se alude. Já na estilização, reproduzem-se os procedimentos estilísticos de outrem, entendidos como "conjunto das recorrências formais tanto no plano de expressão quanto no plano de conteúdo" (FIORIN, 1999, p. 31).

A interdiscursividade (FIORIN, 1999, p. 32-34), por sua vez, está ligada à distinção entre texto e discurso, em viés greimasiano, sendo o primeiro uma "unidade de manifestação" em que os diferentes níveis "do agenciamento do sentido se manifestam e dão a ler", e o segundo, um "patamar do percurso gerativo de sentido em que um enunciador assume as estruturas narrativas" (FIORIN, 1999, p. 30). Embora não possamos nos estender na teorização de Fiorin em sua minúcia na investigação dos patamares do percurso gerativo de sentido, uma consideração mencionada parece importante para nossa discussão da questão da significação: o intertexto não é o plano de conteúdo. A perspectiva da intertextualidade pode escapar a esta discussão argumentando que tudo, para ela, é texto: plano de expressão, de conteúdo, significados, semelhanças, analogias etc. Em cada caso, pode haver intertextualidade.

Com estas primeiras incursões no conceito de intertextualidade, aparece a necessidade de distinguir entre dois termos utilizados, com frequência, como sinônimos ou de maneira intercambiável. A 'intertextualidade' dirá respeito ao conceito em caráter amplo, geral: falaremos da intertextualidade em uma obra, por exemplo, e da intertextualidade como fundamento do sentido (como faz Kristeva, entre outros, retomando o princípio dialógico de Bakhtin). Já o 'intertexto’ será tomado como qualquer um dos textos considerados no espaço dialógico de análise que podemos conceber a partir de Bakhtin (em que a palavra, a voz, o texto, como se viu, são, pelo menos, duplos). Esta é apenas uma regulação de nomenclatura para manter a coerência deste estudo, o que não quer dizer que os autores estudados não 
utilizem os termos de maneiras diferentes (e por vezes conflitantes). Assim, dizia Barthes (2013, p. 45) que "é bem isso o intertexto: a impossibilidade de viver fora do texto infinito" enquanto nós preferiríamos dizer 'a intertextualidade'.

Voltando à teorização de Bakhtin, podemos esquematizar a tipologia apresentada (a partir de Fiorin e adaptada para nossos propósitos) no seguinte quadro.

\begin{tabular}{|c|c|c|c|c|}
\hline \multicolumn{5}{|c|}{ INTERTEXTUALIDADE } \\
\hline \multicolumn{3}{|c|}{ Citação } & \multirow{2}{*}{ Alusão } & \multirow{2}{*}{ Estilização } \\
\hline Linear & Pictórica & $\begin{array}{c}\text { Diluidora } \\
\text { do } \\
\text { contexto } \\
\text { narrativo }\end{array}$ & & \\
\hline
\end{tabular}

Quadro 1 - Tipos de intertextualidade a partir Bakhtin e comentadores

Fonte: Elaborado pelos autores a partir de Fiorin (1999)

Embora a apropriação de Fiorin seja representativa da leitura brasileira de Bakhtin, uma outra filiação histórica e conceitual é quase inevitável de se abordar quando falamos em dialogismo e intertextualidade. Como já dissemos, foi Kristeva quem traduziu o conceito dos textos bakhtinianos para sua própria abordagem semanalítica. Isto é, Kristeva, na verdade, transcria Bakhtin, apropriando-se de sua obra para os propósitos do presente, e inserindo-o no contexto teórico pós-estruturalista (no qual, diga-se de passagem, o pensador russo parece bastante confortável). Voltaremos à especificidade desta distinção de abordagens mais adiante, quando tratarmos desta semanálise barthes-kristevana.

Kristeva vê nos estudos bakhtinianos do dialogismo um modo de observação que se estabelecerá "a. horizontalmente: a palavra no texto pertence simultaneamente ao sujeito da escritura e ao destinatário, e b. verticalmente; a palavra no texto está orientada para o corpus literário anterior ou sincrônico" (KRISTEVA, 2012, p. 141). O eixo horizontal (sujeitodestinatário) foi denominado diálogo (em sentido restrito) e o vertical, ambivalência. Horizontalmente, é "no vaivém entre o sujeito e o outro, entre o escritor e o leitor," que "o autor se estrutura como significante, e o texto, como diálogo de dois discursos". Verticalmente, é no âmbito da ambivalência intertextual que se poderá identificar "a inserção da história no texto e do texto na história" (KRISTEVA, 2012, p. 145), procedimento por meio do qual a semiótica, para a autora, "liquida de vez com as distinções significantesignificado e torna tais conceitos inoperantes na prática literária que se constrói apenas no(s) significante(s) dialógico(s)" (KRISTEVA, 2012, p. 153). 
É fundamental para nossa discussão o reconhecimento de que a significação, considerada por seu aspecto intertextual, lidará com este tipo de entidade: significantes que não escapam à textualidade ao se apresentarem como um significado transcendental, fora do texto, mas, pelo contrário, se constituem da articulação entre os mencionados eixos de observação, abrindo a investigação para um campo dialógico.

Investigar a comunicação enquanto instituída por tais campos dialógicos, como viemos discutindo, mostra-se como uma alternativa ao pensamento linguístico mais tradicional, mas também à 'pesquisa das fontes', 'das influências', à filologia e outras disciplinas ligadas a questões de origem. "Não se trata [...] de determinar um intertexto qualquer, já que tudo se torna intertextual” (SAMOYAULT, 2008, p. 18). Trata-se, isto sim, de abrir um "campo dialógico" (BAKHTIN, 2016, p. 150) - campo que, como dirá Barthes, não tem origem nem fim. Com isso, nos afastamos, por exemplo, da perspectiva de Harold Bloom, outro importante pensador do dialogismo da literatura, que se volta, contudo, para as questões de influência na produção poética (conforme GENETTE, 1989, p. 11 e BROWN, 1991).

Vários outros teóricos se debruçaram sobre a questão do caráter dialógico da literatura. Entre eles, é notável a intervenção de Gérard Genette, que oferece mais uma perspectiva para a passagem - que neste capítulo sublinhamos - do intratextual ao intertextual. Postulando o objeto da poética, o autor francês aponta não para o texto considerado em sua singularidade, mas para a "transcendência textual" que chama de transtextualidade (GENETTE, 1989, p. 9), e que definiu como "tudo que põe o texto em relação, manifesta ou secreta, com outros textos" (GENETTE, 1989, p. 10). Podemos representar em um quadro sua tipologização da transtextualidade, em que o intertexto é categoria bastante restrita:

\begin{tabular}{|c|c|c|c|c|c|c|c|}
\hline \multicolumn{8}{|c|}{ Transtextualidade } \\
\hline \multicolumn{3}{|c|}{ Intertextualidade } & \multirow{2}{*}{$\begin{array}{c}\text { Arqui- } \\
\text { textualidade }\end{array}$} & \multirow{2}{*}{$\begin{array}{c}\text { Para- } \\
\text { textualidade }\end{array}$} & \multirow{2}{*}{$\begin{array}{c}\text { Meta- } \\
\text { textualidade }\end{array}$} & \multicolumn{2}{|c|}{ Hipertextualidade } \\
\hline Citação & Plágio & Alusão & & & & $\begin{array}{c}\text { Transformação } \\
\text { simples }\end{array}$ & $\begin{array}{l}\text { Imitação } \\
\text { complexa }\end{array}$ \\
\hline
\end{tabular}

Quadro 2 - Tipos de intertextualidade em Genette

Fonte: Elaborado pelos autores a partir de Genette (1989).

Não pretendemos, aqui, retomar todas estas categorias; apenas apontar que o tratamento do dialogismo, conforme o viemos percorrendo, parece tender a uma abordagem tipológica, que determina as diferentes relações intertextuais possíveis. O fundamento da “semanálise” (KRISTEVA, 2012), porém, estará não na tipologização, mas na textualidade 
que, em sua concepção, atravessa e engendra os tipos que podem ser institucionalizados como estruturalidades vigentes. Ou seja, se o dialogismo é o texto entendido como cruzamento de superfícies textuais (não há texto isolado dos outros textos), os tipos de cruzamento serão incontáveis. Por isso Kristeva e Barthes propunham seguir uma textualidade específica na medida em que ela se desenrola, atravessando intertextos, de forma imanente. É necessário, aquém do próprio intertexto, para entender sua função nesta lógica, retomar o conceito de texto.

\section{TEXTUALIDADE E SIGNIFICÂNCIA}

Barthes e Kristeva são nomes ligados a uma virada pós-estruturalista no pensamento semiótico dos anos 60 que procuraremos apresentar aqui pelos conceitos de texto e significância. Para Barthes (1974, p. 2), tratava-se de encaminhar a semiótica no rumo de uma "crítica do signo" que abre caminho para uma "nova teoria do texto".

A concepção clássica (pré-semiótica) do signo vai ser denunciada por Barthes como se baseando na busca de um significado e de uma origem que, implicitamente, coincidem. Conforme o autor, há duas "legalidades" que fundamentam as práticas de interpretação clássicas: as "legalidades" da literalidade (fidelidade significante das versões sucessivas à original) e da semântica (lei que regula uma relação entre representante e representado, signo e referente). As duas legalidades na verdade se confundem na lógica sígnica pré-semiótica da obra literária (BARTHES, 1974, p. 1). O signo funciona, aqui, como "encerramento" que "freia o sentido, o impede de tremer, de se dividir, de divagar" (BARTHES, 1974, p. 1).

Já a lógica da textualidade foi proposta por Barthes (1989a, p. 60) como uma alternativa à redução do texto às legalidades literais e semânticas. Barthes (1989b, p. 54) diz que a garantia de unidade do texto não está em sua origem, mas em sua destinação: é o leitor. E isto não quer dizer que lidamos com um fenômeno mental. Mas sim que é impossível "viver fora do texto infinito" que é, na verdade, um "intertexto" (BARTHES, 2013, p. 45). O texto transforma-se em "campo metodológico" (BARTHES, 1989a, p. 57), em que a restituição do intertexto, paradoxalmente, abole toda relação de herança ou influência (BARTHES, 1989b, p. 61). Passando além do "freio" sígnico, trata-se de uma lógica da disseminação.

Esta noção de texto pode envolver "pluralidade". Contudo "não é [...] coexistência de significado, mas passagem, atravessamento". Uma operação que permanece na imanência 
"integralmente simbólica" do texto, diagramatizando um "infinito adiamento do significado" (BARTHES, 1989b, p. 59). É neste texto intertextual que a semanálise investigaria o movimento de significância (KRISTEVA, 2012, p. 3), entendido como atravessamento e produtividade de sentido.

Para compreender a distinção entre significação e significância, podemos pensar na distinção entre feno e genotextualidade. O "fenotexto" é aquele tipo de estrutura - "linguagem que serve para comunicar" - que obedece a regras de comunicação e pressupõe um sujeito de enunciação e um destinatário (KRISTEVA, 1984, p. 87). Contudo, este fenotexto, dimensão superficial (KRISTEVA, 2012, p. 283) comunicativa, que estuda um trabalho de transmissão ocorrido na superfície, oculta o trabalho de produção que o "genotexto" opera. O genotexto está ligado a uma redistribuição destrutiva-construtiva das estruturas e códigos da comunicação (KRISTEVA, 2012, p. 281).

Esta é a modalidade propriamente "produtiva" de significação ${ }^{3}$, que só se apresenta, contudo, em uma série de rastros, fenômenos "encerrados" por um "freio" sígnico (KRISTEVA, 1984, p. 36). Daí, novamente, a importância do dialogismo que, para Kristeva (2012, p. 148), "implica um rompimento formal relativamente à norma"; implica "a linguagem e uma outra lógica", implica um fenômeno comunicacional da ordem não da transmissão de significados, mas da produção de sentido. Lendo Bakhtin, Kristeva enfatiza que, se o texto é sempre atravessamento, ele é, por isso mesmo, não só uma transmissão de significados, mas uma "produtividade" (KRISTEVA, 2012, p. 203), um remanejamento destrutivo-construtivo das possibilidades e normas cristalizadas ${ }^{4}$ de determinada linguagem.

O conceito de signo é, portanto, problematizado desde esta perspectiva semanalítica, que retoma a noção de produtividade do materialismo histórico. Os produtos de uma sociedade capitalista só aparecem enquanto valor-de-troca, e por sua circulação poder-se-ia, conforme a teoria marxista, estudar determinada sociedade. Mas este valor-de-troca opera uma abstração, omitindo as suas relações de produção. Ele não dá conta de um trabalho prévalor, "aquém da mercadoria produzida e posta em circulação na cadeia comunicativa" (KRISTEVA, 2012, p. 28). Analogamente, o fenotexto omite as relações genotextuais que o trabalham.

\footnotetext{
${ }^{3}$ Kristeva acusa a gramática gerativa de Chomsky, neste sentido, de não gerar nada. A significância está ligada, em seus fundamentos, ao materialismo histórico, e, por isso, a ação revolucionária da comunicação não está em seus conteúdos estruturados, mas nas genotextualidades da ordem da experimentação com os campos intersemióticos (de materialidades heterogêneas) que constituem estruturalidades.

4 Saussure (1995, pp. 29, 31) falava em uma "cristalização social" que liga "imagem auditiva e conceito" (significante e significado).
} 
É necessário exemplificar esta lógica operacional kristevana da significação - ou antes de significância. Como vimos, a significação se expressa na dimensão comunicativa fenotextual, embora seja trabalhada e refundada por um movimento genotextual irredutível à significação estruturada. Porém, os exemplos a este respeito devem ser bastante específicos. Porque Kristeva só pôde reconhecer esse movimento prévio à ordem da significação da comunicação a partir de um tipo de caráter autorreflexivo do texto moderno (desde Mallarmé a Phillipe Sollers), que "presentifica [...] o trabalho da significância" (KRISTEVA, 2012, p. 10), dando a ver o movimento genotextual produtivo que a faceta comunicativa da "obra" oculta. Este tipo de texto "representa, em sua narração [...] os princípios teóricos, epistemológicos ou políticos nos quais o que é escrito pode se dizer” (KRISTEVA, 2012, p. 288), e exige uma reflexão "sobre o significante-produzindo-se em texto" (KRISTEVA, 2012, p. 277).

A significância, portanto, situa-se no nível da materialidade da linguagem: o texto faz uma exploração das potencialidades comunicacionais da literatura (por exemplo), propondo um "praticar no significante" (KRISTEVA, 1974, p. 15). Passando da significação, que comunica por meio do fenotexto codificado, o estudo da significância volta-se, assim, a uma produtividade genotextual que é um remanejamento das normas estruturais da língua. Neste sentido é que Phillipe Sollers, por exemplo, pôde problematizar seu romance por meio da lógica diferencial leibniziana (KRISTEVA, 2012, p. 298), e Mallarmé pôde operar uma série de violações de leis lógicas (KRISTEVA, 2012, pp. 256-268) para a construção de sua própria fenotextualidade poética.

Daí a proposta micropolítica da semanálise para a comunicação: uma política interior à comunicação, que atua no nível de suas regularidades de significação, trabalhando-as genotextualmente, e não somente no nível dos conteúdos representados. Esta é a intervenção política efetivamente materialista na comunicação, "transformando a matéria da língua (sua organização lógica e gramatical), para aí transpondo a relação das forças sociais da cena histórica" (KRISTEVA, 2012, p. 4).

\section{CONSIDERAÇÕES: DA INTERTEXTUALIDADE À SIGNIFICÂNCIA DA COMUNICAÇÃO}


Conforme se pode discuti-la neste espaço, a semanálise ${ }^{5}$ aparece como uma mesma proposta de passagem expressa de pelo menos três maneiras: (1) dos estudos de significação aos de significância; (2) de uma lógica do signo como restituição de sentido a uma lógica do texto como campo metodológico de disseminação; (3) da análise de uma comunicação intersubjetiva estruturada (fenotexto) ao movimento redistributivo que trabalha e fundamenta (genotexto) esta comunicação. Mas como vislumbrar a dimensão 'oculta' de cada uma dessas aparentes oposições - se concedemos, com Kristeva, que a comunicação ${ }^{6}$ é justamente um tipo de ocultamento (em prol de uma linguagem estruturada, transmissiva, que remete a um sujeito de enunciação pressuposto) do trabalho de diferenciação e disseminação do sentido? Este o papel da intertextualidade como estratégia de análise do texto. A textualidade, a significância, e o genotexto são tentativas de apontar para uma faceta produtiva da comunicação que, oculta no discurso monológico codificado, só pode aparecer por meio de um tipo de diagramatização ${ }^{7}$ do espaço intertextual.

Isso implica, para Kristeva, uma "dinamização do estruturalismo". Se este se detinha sobre os aspectos de significação de determinado texto-objeto, desde a perspectiva intertextual um texto não é, mas "se elabora" em relação a outro, no rumo de uma translinguística. A palavra (e esta é uma das citações mais populares acerca da intertextualidade) deixa de aparecer como ponto (sentido fixo) para se tornar um “cruzamento" dialógico de textos (KRISTEVA, 2012, p. 140) ou simplesmente materialidades comunicacionais.

A intertextualidade aparece, pois, da perspectiva semanalítica, tanto como condição de todo texto - havendo sempre linguagem antes dele e somente linguagem ao seu redor (BARTHES, 1974, p. 6) - quanto como perspectiva teórico-metodológica de análise. Esta, para estudar o aspecto produtivo que se oculta na comunicação transmissiva fenotextual, investiga um fenotexto dilacerando-o em um espaço intertextual em que se podem vislumbrar suas relações genotextuais de transgressão micropolítica da comunicação.

Cabe apenas acrescentar que esta concepção de um espaço intertextual, que tem destaque na obra de Kristeva desde os mencionados textos fundadores de 1966 e 67, é revisada pela autora em sua tese de 1974 , que nos parece o ponto culminante da primeira parte

\footnotetext{
${ }^{5}$ A pesquisa "semanalítica" foi assim denominada porque os processos semiológicos fazem parte de um mesmo contínuo com os processos sociais, históricos e econômicos, mas também com os processos de subjetivação. Trata-se de uma influência teórica dupla no pensamento semiológico de Kristeva: da psicanálise freud-lacaniana e do materialismo histórico. Neste espaço, não pudemos desenvolver mais que este último aspecto.

${ }^{6} \mathrm{O}$ comunicacional aparece como função do fenotexto (KRISTEVA, 2012, p. 283).

${ }^{7}$ Que é uma "produtividade”, uma “elaboração” (KRISTEVA, 2012, p. 109 e p. 140).
} 
de sua carreira, e que articula suas ideias desenvolvidas até este ponto acerca da semiótica, da psicanálise e do materialismo dialético. A autora argumenta, então, que a linguagem poética impede "que o tético ${ }^{8}$ devenha teológico, que sua imposição oculte o processo semiótico que o produz" (KRISTEVA, 1974, p. 58). Isto é, a linguagem poética impede que a significação estruturada em fenotexto comunicativo oculte o movimento material da significância que a produz. Se a linguagem poética se impõe diante do sentido ("porte atteinte au sens"), a intertextualidade aparecerá como uma das operações específicas pelas quais se efetuam essas “corrupções do simbólico" (KRISTEVA, 1974, p. 59). A operação intertextual, ou "passagem de um sistema de signos a um outro" é, neste ponto, revisada:

porque este termo [de 'intertextualidade'] foi frequentemente entendido no sentido banal de 'crítica das fontes' de um texto, nós preferimos aquele de transposição, que tem a vantagem de precisar que a passagem de um sistema significante a outro exige uma nova articulação do tético - da posicionalidade enunciativa e denotativa9 ${ }^{9}$ (KRISTEVA, 1974, p. 60).

Toda prática significante, portanto, é entendida como um "campo de transposições de diversos sistemas significantes (uma intertextualidade)" cujo "lugar de enunciação e objeto não são jamais únicos, plenos e idênticos a si mesmos, mas sempre plurais", resultando de uma "polivalência semiótica", uma "pertença a diversos sistemas semióticos" (KRISTEVA, 1974, p. 61). É neste espaço de práticas significantes que pensamos ser interessante analisar contemporaneamente a intertextualidade da comunicação, que constantemente se diferencia de si própria em processos de significância cujo traçado transposicional é nosso desafio percorrer.

\section{REFERÊNCIAS}

BAKHTIN, M. Problems of Dostoevsky's poetics. Minneapolis, EUA: University of Minnesota Press, 1984.

BAKHTIN, M. Marxismo e filosofia da linguagem. São Paulo, SP: Hucitec, 1997.

BAKHTIN, M. Os gêneros do discurso. São Paulo, SP: Editora 34, 2016.

\footnotetext{
${ }^{8} \mathrm{O}$ "evento tético [...] constitui, contra o processo pulsional, o animal simbólico e a sociedade" (KRISTEVA, 1975, p. 14). O conceito procede da teorização fenomenológica de Husserl.

${ }^{9}$ Tradução nossa. No original: "Puisque ce terme [intertextualidade] a été souvent entendu dans le sens banal de 'critique des sources' d'un texte, nous lui préférons celui de transposition, qui a l'avantage de préciser que le passage d'un systeme signifiant à un autre exige une nouvelle articulation du thétique - de la positionalité énonciative et dénotative".
} 
BARROS, D. L. P. Dialogismo, polifonia e enunciação. In: BARROS, D. L. P.;FIORIN, J. L. (Orgs.) Dialogismo, polifonia, intertextualidade. São Paulo, SP: Edusp, 1999.

BARTHES, R. Théorie du texte. In: Encyclopaedia Universalis. 1974.

BARTHES, R. The death of the author. In: The rustle of language. Berkeley, EUA: University of California Press, 1989a.

BARTHES, R. From work to text. In: The rustle of language. Berkeley, EUA: University of California Press, 1989b.

BARTHES, R. O prazer do texto. São Paulo, SP: Perspectiva, 2013.

BROWN, M. Remaking the Past: musical modernism and the influence of the tonal tradition by Joseph Straus reviewed by Matthew Brown. In: Intégral, Vol. 5, 1991.

DUCROT, O. \& TODOROV, T. Dictionnaire encyclopédique des sciences du langage. Paris, França : Éditions du Seuil, 1972.

FIORIN, J. L. Polifonia textual e discursiva. In: BARROS, D. L. P.; FIORIN, J. L. (Orgs.) Dialogismo, polifonia, intertextualidade. São Paulo, SP: Edusp, 1999.

GENETTE, G. Palimpsestos - la literatura en segundo grado. Madrid, Espanha: Taurus, 1989.

HJELMSLEV, L. Ensaios lingüísticos. São Paulo, SP: Perspectiva, 1991.

KRISTEVA, J. La révolution du langage poétique. Paris, França: Éditions du Seuil, 1974.

KRISTEVA, J. Pratique signifiante et mode de production. In : KRISTEVA, J. (org.) La Traversée des Signes. Paris, França: Éditions du Seuil, 1975.

KRISTEVA, J. Revolution in poetic language. Nova Iorque, EUA: Columbia University Press, 1984.

KRISTEVA, J. Introdução à semanálise. São Paulo, SP: Perspectiva, 2012.

LEMOS, C. A função e o destino da palavra alheia. In: BARROS, D. L. P.; FIORIN, J. L. (Orgs.)

Dialogismo, polifonia, intertextualidade. São Paulo, SP: Edusp, 1999.

LOPES, E. Discurso literário e dialogismo em Bakhtin. In: BARROS, D. L. P.; FIORIN, J. L. (Orgs.) Dialogismo, polifonia, intertextualidade. São Paulo, SP: Edusp, 1999.

MOI, T. The Kristeva reader. Nova Iorque, EUA: Columbia University Press, 1986.

MOTTA, L. T. Roland Barthes: uma biografia intelectual. São Paulo, SP: Iluminuras, 2011.

SAMOYAULT, T. A intertextualidade. São Paulo, SP: HUCITEC, 2008.

SAUSSURE, F. Cours de linguistique générale. Paris, França : Payot \& Rivages, 1995. 
Professor do Programa de Pós-Graduação em Comunicação da Universidade Federal do Rio Grande do Sul.

Pós-doutorado na Université de Paris III. Doutor em Ciências da Comunicação pela Unisinos. Mestre em Semiótica pela Unisinos.

\section{Cássio de Borba Lucas}

Doutorando em Comunicação pelo Programa de Pós-Graduação em Comunicação da Universidade Federal do Rio Grande do Sul. Mestre em Comunicação e Informação pelo PPGCOM-UFRGS.

Graduado em Comunicação Social - Jornalismo.

Bolsista CAPES.

Esta obra está licenciada sob uma Licença Creative Commons. 